\begin{tabular}{|c|cc|}
\hline & PORT-SAID ENGINEERING RESEARCH JOURNAL \\
Faculty of Engineering - Port Said University
\end{tabular}

\title{
Numerical Assessment of Pile Capacity in Loose Sand in North-Eastern Egypt
}

\author{
Tarek N. Salem ${ }^{1}$, Khaled M. Abdelatty ${ }^{2}$, Ahmed A. Abdalla ${ }^{3}$
}

\begin{abstract}
At some coastal areas in Egypt, especially Port Said and Damietta, there are layers of surface loose to medium silty sand with traces of fragments of seashells overlying a very deep soft clay layer. The construction of shallow foundations over such soil formation is difficult and in some cases is not possible due to the high soil compressibility, large settlements, low bearing capacity, and near surface groundwater. In such case, short small diameter piles could be used especially under low rise structures to transmit the structure loads with much lower settlements. A finite element-based numerical analysis using ADINA software (Version 9.4.2) [4] is used to analyze and study the behavior of piles in such soil formations. Results indicated that both pile diameter and embedment length in loose sand have significant effect on the pile capacity and settlement on the other hand pile embedded length in soft clay layer has no effect on either pile capacity or pile settlement. One of the key findings of this study is that most of the load in this case is carried by the pile is transmitted to soil by skin friction so that the choice of using pile foundation in such soil formation is practical to some extent.
\end{abstract}

Keyword: Piles; Loose Sand; Soft Clay; Skin Friction; Numerical Analysis, ADINA.

\section{1- INTRODUCTION}

Geotechnical engineers consider soft clay as problematic soil type due to its high settlements, low shear strength and bearing capacity which leads to low allowable surface loads. Therefore, soil structure interaction in this scenario is complex in both short and long-term conditions, Hamed et al. (2017) [13].

In Egypt, Nile River flows from the south and forms a delta in northern Egypt and extends from east Alexandria to Port Said. Nile delta is formed by slowly settling of clay particles at the mouth of the river where the water is slowing down and soft clay deposit is accordingly formed. The ancient branches of the Nile River are also formed along the northeastern delta of Egypt and extend east of Port Said, known as the Plain of Tina. Figure (1) illustrates the location of El-Tina Plain on Egypt's map, El-Gammal (2013) [11].

The depth of soft clay deposit in El-Tina plain area extends for about fifty meters below ground surface. Many studies focused on the history of the soil formation of the northern Nile Delta in general and the Tina plain in particular, Ibrahim (2002) [20]; Stanley (2003) [28], Abdeltawab and Hussein (2008) [3], Barakat (2010) [9] and Ismail and Ryden (2012) [21].

\footnotetext{
${ }^{1}$ Professor, Faculty of Engineering, Zagazig University, Egypt, Email:nageeb2@yahoo.com

${ }^{2}$ Lecturer, Faculty of Engineering, Zagazig University, Egypt, Email: khaled.abdelatty@gmail.com

${ }^{3}$ Demonstrator Faculty of Engineering, Zagazig University, Egypt,

,Email: a adel_10466@yahoo.com
}

These studies indicated that the soft clay in this area has been deposited in similar geological conditions. Therefore, it is believed that their geotechnical properties are also similar. Hamed et al. (2017) [13], created an ideal profile to represent the El-Tina plain subsurface conditions, as shown in Figure (2). The idealized profile consists of a surface layer of soft clay with a depth down to $5 \mathrm{~m}$ followed by a layer of loose to medium dense sand with some sea shells fragments and some silt overlaying a deep layer of soft to medium stiff clay with depths extending down to larger than $50 \mathrm{~m}$ in some cases. A similar soil profile is used to model the soil in the current study.

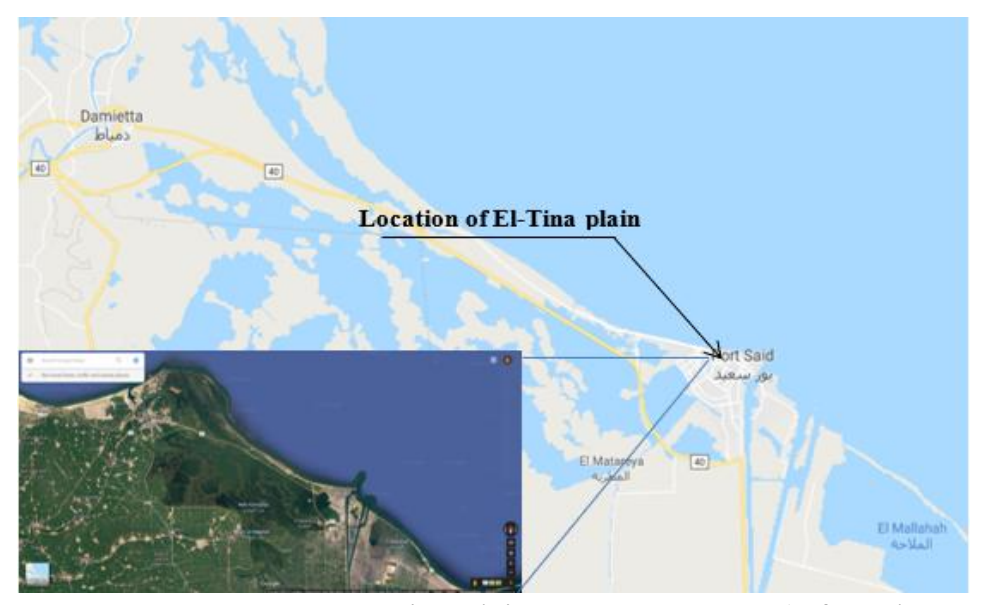

Figure (1): Location of El-Tina Plain on Egypt's Map, (After El Gammal (2013) [11]) 


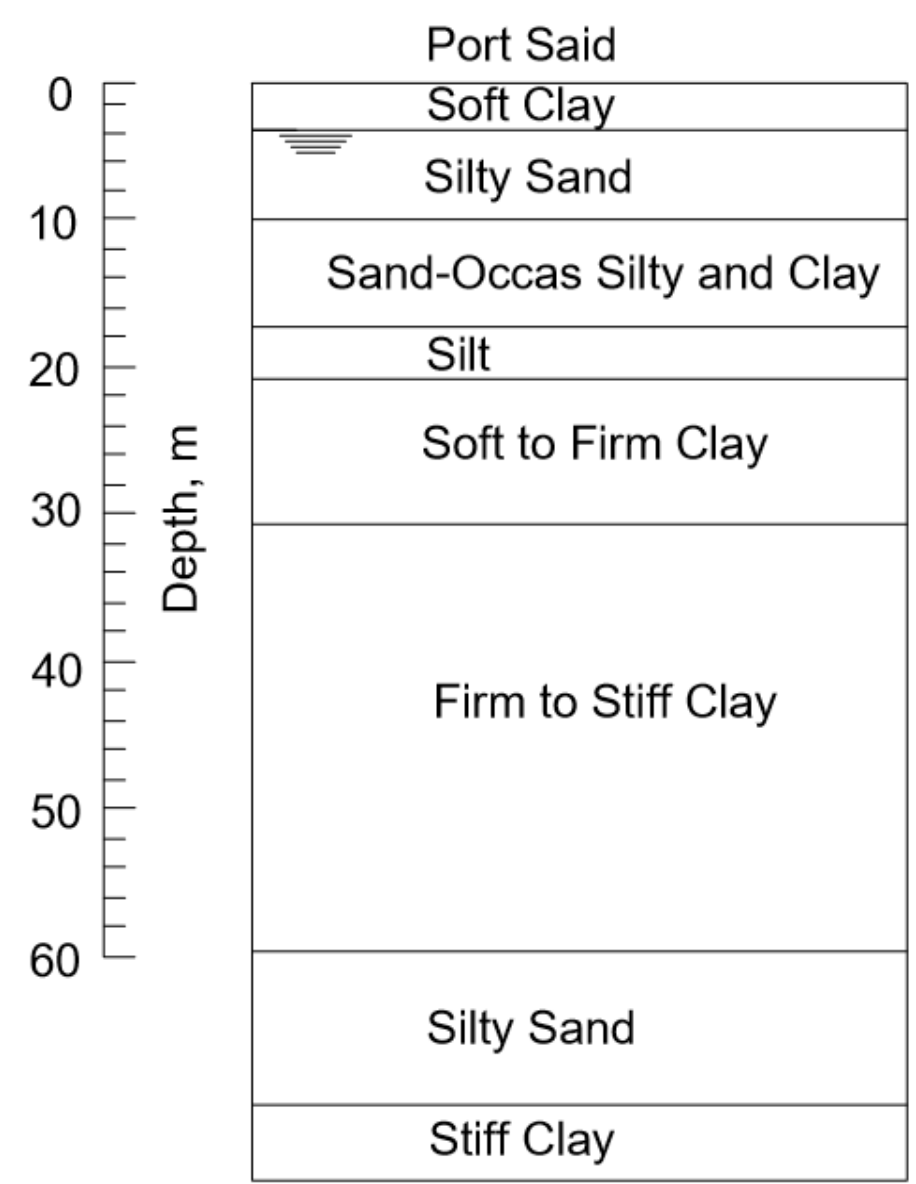

Figure (2): Soil Stratification of Port-Said, After Hamza and Shahien (2013) [17].

Pile foundations are considered relatively more expensive than shallow foundations, so they should be selected only when shallow foundations cannot satisfy an acceptable bearing capacity and settlement safety during the service life of the structure. These two independent design criteria can arise because of the nature and magnitude of structural loads, settlement-sensitive structures and soil type. Thus, the main goal of the piles in this case is to obtain design standards by transferring structural loads to deep, stable and stiffer soil layers, (Hammam, et al 2017) [16].

The case can be more complex as in the current study when the topsoil layers consists of loose to medium sand with relatively small thickness followed by and extended soft clay layer. This complexity adds more uncertainty in the pile behavior, therefore, using mainly friction piles needs to be studied and analyzed in details to account for the effect of the presence of the underlying deep soft clay layers.

\section{2- NUMERICAL MODEL}

\section{2-1-Finite Element Program}

The finite element analysis is conducted using Automatic Dynamic Incremental Non-linear Analysis (ADINA) computer program (ADINA R\& D, 2018) [4]. The program allows different 2-D, 3-D and axisymmetric models. Twodimensional (2D) finite element models (FEM) are developed to study the behavior of the axially loaded piles in the soil with profile shown in Figure (3) to simulate the behavior of pile in such soil formation. A fully coupled (soil and fluid) 4-noded element from the ADINA's element library is utilized. This element type is believed to offer high quality stress results and to be adequate for failure situations.

The base of the model is considered to be fixed in the horizontal and vertical directions, while the side boundaries are fixed in the horizontal direction only allowing for the soil to settle freely, as shown in Figure (3). Based on the analytical solution proposed by Randolph and Wroth (1978) [25], to evaluate the deformation of soil around a pile shaft, twodimensional solid elements are used to represent the soil and pile elements. Since the bending effects are not significant, the 4-node rectangular element is used. A zone of very fine mesh is employed around and below the pile tip equivalent to three times the pile diameter in each direction.

It this study the concrete pile is modeled by using the linear elastic isotropic material model or the concrete model. The linear elastic isotropic model is more sufficient when the deformation is relatively small but when the load approaches the concrete failure load it's useful to use the concrete model. As mostly all models didn't approach the concrete failure load, the linear elastic isotropic model is used to model the pile element. The Mohr-Coulomb (MC) material model is used to characterize loose to medium sand. On the other hand, CamClay material model is used to model the soft and medium stiff clay behavior.

\section{2-2- Modeling of Construction Sequence Analysis Stages}

The construction sequence effect is modeled in order to simulate the sequential loading of soil and pile. The main phases of loading can be presented in the following sequence:

1. Soil settlement due to its own weight under geo-static pressure;

2. Pile installation, in which the soil elements at the pile location are set to death followed by the birth of the pile elements; and

3. Pile loading process 


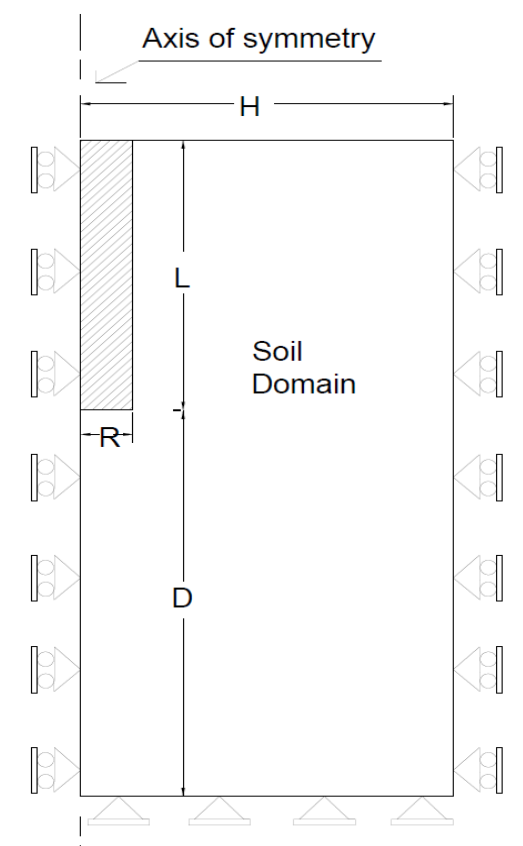

(a): The Boundary Conditions and Dimensions Used in The Numerical Modeling

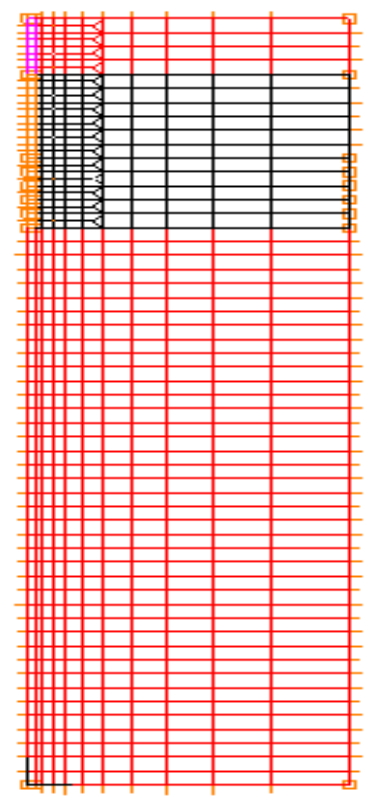

(b): Finite Element Mesh.

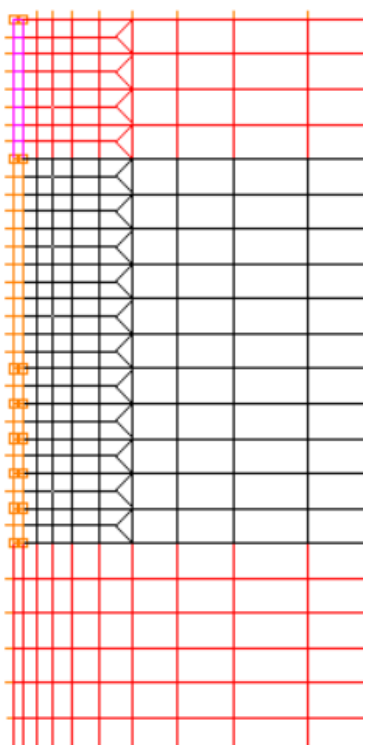

(c): Zoom in Finite Element Mesh Around Pile and Surrounding Soil.
Figure (3): Schematic View of the Boundary Conditions, Dimensions and Finite Element Mesh Used in the Numerical Modeling.

\section{2-3-Verification of the Proposed Finite Element Model}

The proposed finite element model is verified herein against full-scale pile load tests performed by Hammam et al.
(2017) [15]. Hammam et al. (2017) [15], conducted a full-scale pile load test north of Nile delta in Egypt to analyze the loadsettlement behavior of bored piles with lengths equal to $27.0 \mathrm{~m}$ and longer to support raft foundations of twelve stories residential buildings. The soil profile in their study consisted of a top layer of loose to medium dense sand with thickness of $8 \mathrm{~m}$ to $10 \mathrm{~m}$ depth, overlying a layer of deep compressible clay which extends down to $40 \mathrm{~m}$, as shown in Table (1). The ground water table is found to be near the ground surface, as shown in Figure (4). Boreholes are drilled down to $60.0 \mathrm{~m}$ from the ground surface. Six (CPTU) tests are also conducted down to $25 \mathrm{~m}$ depth to measure the different soil properties. Pile load tests are conducted on different types of piles with diameters of 0.60 and $0.70 \mathrm{~m}$. Static load tests are continued till reaching $2000 \mathrm{kN}$, which is equal to $250 \%$ of the design pile load capacity.

This case study is numerically modeled herein in this paper to verify the proposed numerical model and show its ability to accurately model the full-scale field test results performed by Hammam et al. (2018) [15].

Table (1): Field Soil Profile Properties Used in the Numerical Analysis.

\begin{tabular}{|c|c|c|c|c|c|}
\hline \multirow{2}{*}{$\begin{array}{c}\text { Layer } \\
\text { Depth } \\
(\mathrm{m})\end{array}$} & \multirow[b]{2}{*}{$\begin{array}{c}\text { Layer } \\
\text { Description }\end{array}$} & \multicolumn{4}{|c|}{ Layer Properties } \\
\hline & & $\begin{array}{c}\gamma \\
\left(\mathrm{kN} / \mathrm{m}^{3}\right)\end{array}$ & $\begin{array}{c}\mathrm{C}_{\mathrm{u}} \\
(\mathrm{kPa})\end{array}$ & $\emptyset^{\circ}$ & $\begin{array}{c}\mathrm{E}_{\mathrm{s}} \\
(\mathrm{MPa})\end{array}$ \\
\hline $\begin{array}{c}0.00- \\
2.00\end{array}$ & $\begin{array}{l}\text { Topsoil layers } \\
\text { (Fill) }\end{array}$ & 16.0 & 5.0 & 15.0 & 0.60 \\
\hline $\begin{array}{c}2.00- \\
8.00\end{array}$ & $\begin{array}{l}\text { Loose sand to } \\
\text { medium sand }\end{array}$ & 18.0 & 0.0 & 32.0 & 15.0 \\
\hline $\begin{array}{l}8.00- \\
12.00\end{array}$ & Loose sand & 17.0 & 0.0 & 30.0 & 10.0 \\
\hline $\begin{array}{c}12.00 \\
- \\
40.00\end{array}$ & $\begin{array}{l}\text { Soft to medium } \\
\text { silty clay }\end{array}$ & 16.50 & 15.0 & 0.0 & 1.50 \\
\hline
\end{tabular}

- $\quad \gamma$ is the soil saturated unit weight.

- $\mathrm{C}_{\mathrm{u}}$ is the undrained shear strength.

- $\phi$ is the angle of shearing resistance.

- $\mathrm{E}_{\mathrm{s}}$ is the soil modulus $\left(\mathrm{E}_{\mathrm{s}}=1 / \mathrm{m}_{\mathrm{v}}\right.$, where $\mathrm{m}_{\mathrm{v}}$ is the compressibility modulus). 

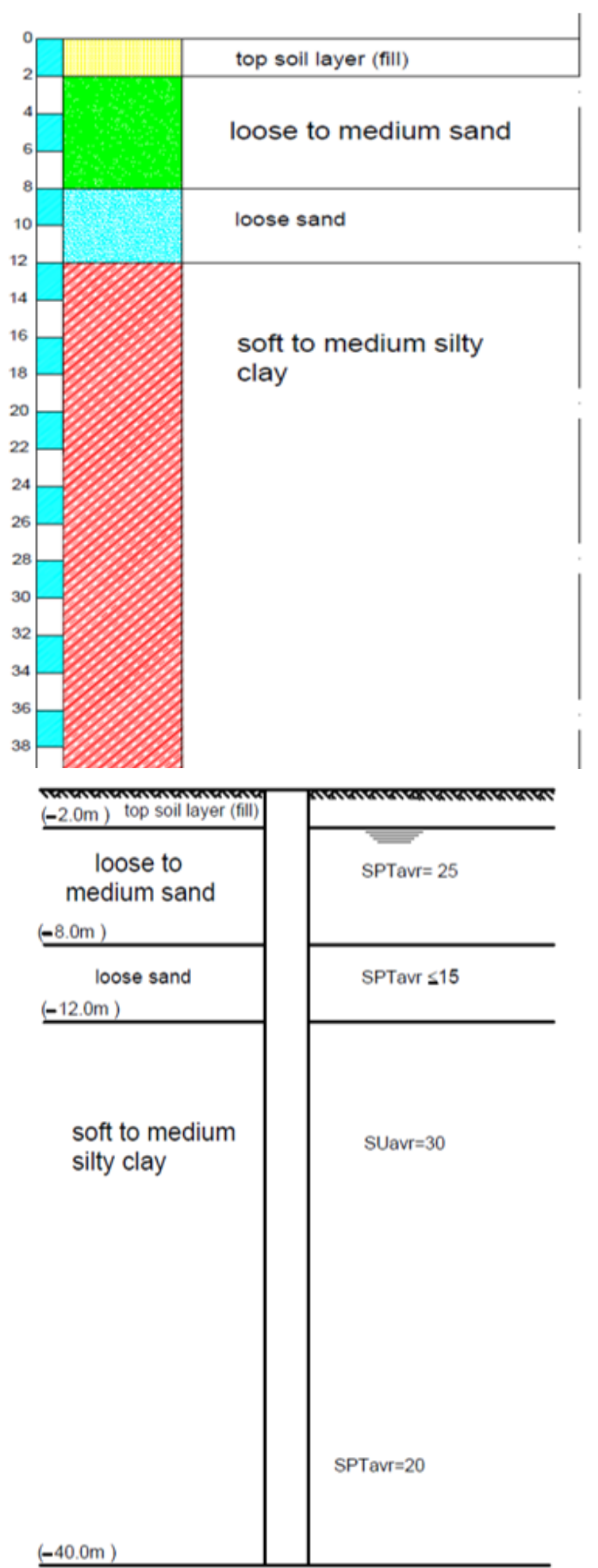

Figure (4): Borehole Data and Soil Properties (After Hammam et al., 2017) [15].

A comparison between results of the finite element model for bored piles in the same soil profile and pile properties and the load settlement relationship of the pile load test are presented in Figure (5). Results of the numerical model, presented in this paper, show a computed settlement of 13.25 $\mathrm{mm}$ under maximum load of $2000 \mathrm{kN}$ while the measured settlement from the pile load test at the same load is $13.0 \mathrm{~mm}$, with a maximum difference not exceeding $9.1 \%$ during all the loading stages of the test. Thus, the numerical model results are found to be in good agreement with the field pile load test results.

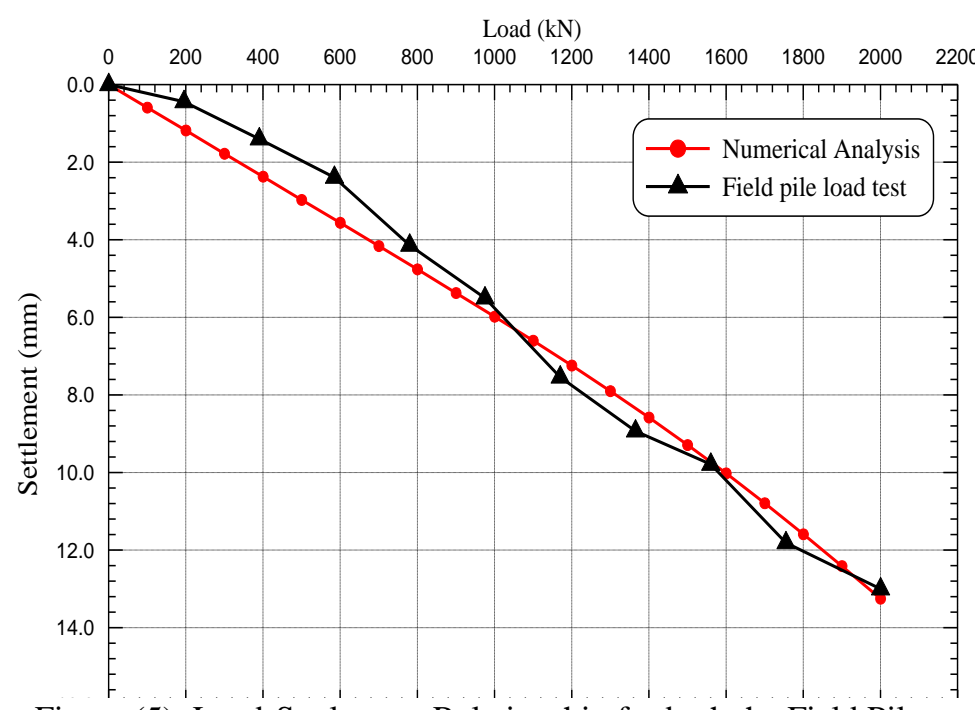

Figure (5): Load-Settlement Relationship for both the Field Pile Load Test, and the Numerical Analysis in the Current Research.

The computed net settlement at the pile head due to pile loading is equal to $13.25 \mathrm{~mm}$, as shown in Figures (6). Figure (6) shows colored contour shading of pile settlements and contour shading of the vertical stresses within the pile and soil domain due to the pile load test and also shows their distribution within the soil domain at the pile loading stage. The shading emphasizes that most of the pile load and consequently stresses on the soil are transferred as skin friction around the pile shaft with much lower stresses around the pile tip. Good agreement is noticed between the pile load test results and the proposed numerical model, especially under higher stress levels, whereas small differences are noticed at lower stress levels. 


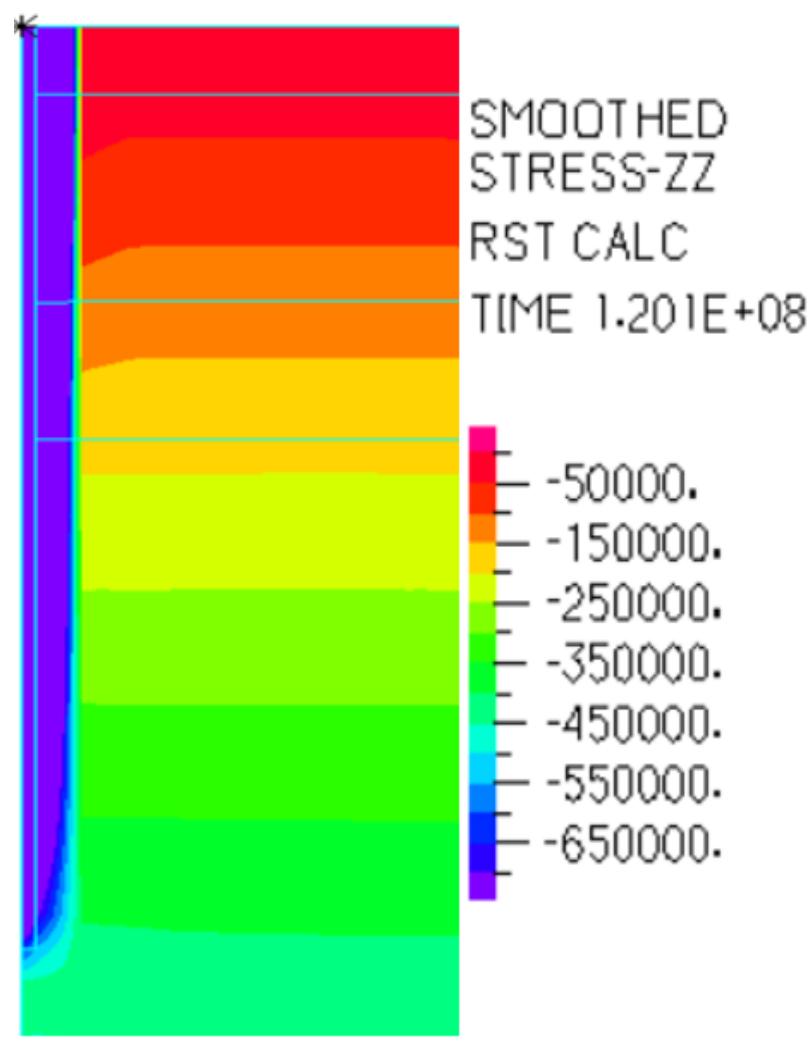

(a): Vertical Stresses Around the Pile and Its Tip.

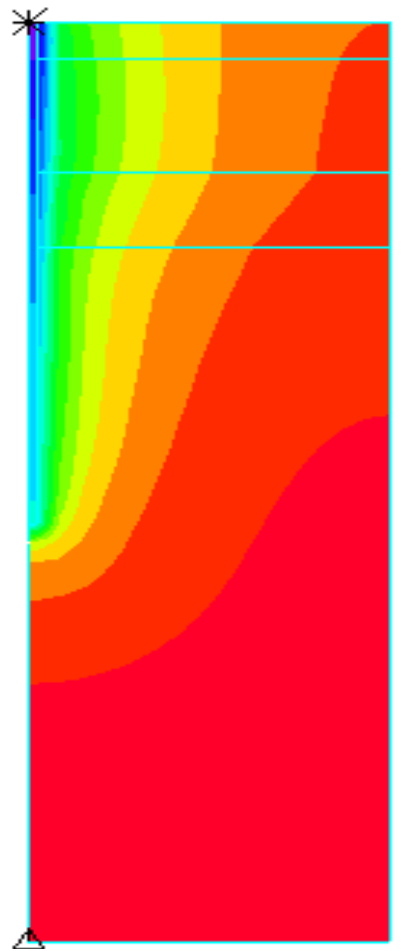

Z-DISPLACEMENT

Response combination

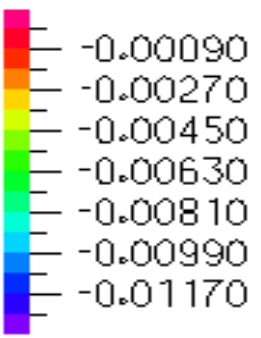

MAXIMUM

$\triangle 0.000$

NODE 57

MINIMUM

* -0.01325

NDDE 55

(b): Net Settlement Shading Contours Around the Pile.

Figure (6): Colored Contour Shading of Vertical Stresses and Settlements Around the pile.

\section{3- NUMERICAL MODEL OF THE CASE STUDY}

The special soil formation at Port Said and some zones of Damietta and new Damietta are interesting case studies which needs to be specifically studied, where the main soil formation is layers of loose to medium silty sand overlying a very deep soft clay layer Hamed, et al., (2017) [13]. This specific soil formation is studied herein in this research to assess the pile performance and investigate the feasibility of using piles constructed in and resting within the upper loose sand layer in such areas. In this specific case study, the upper loose sand layer with thickness extending from $4.0 \mathrm{~m}$ down to about $15.0 \mathrm{~m}$ is, underlain by a deep compressible clay layer which extends down to about $50 \mathrm{~m}$, while the ground water is found near the ground surface, as shown in the Figure (7).

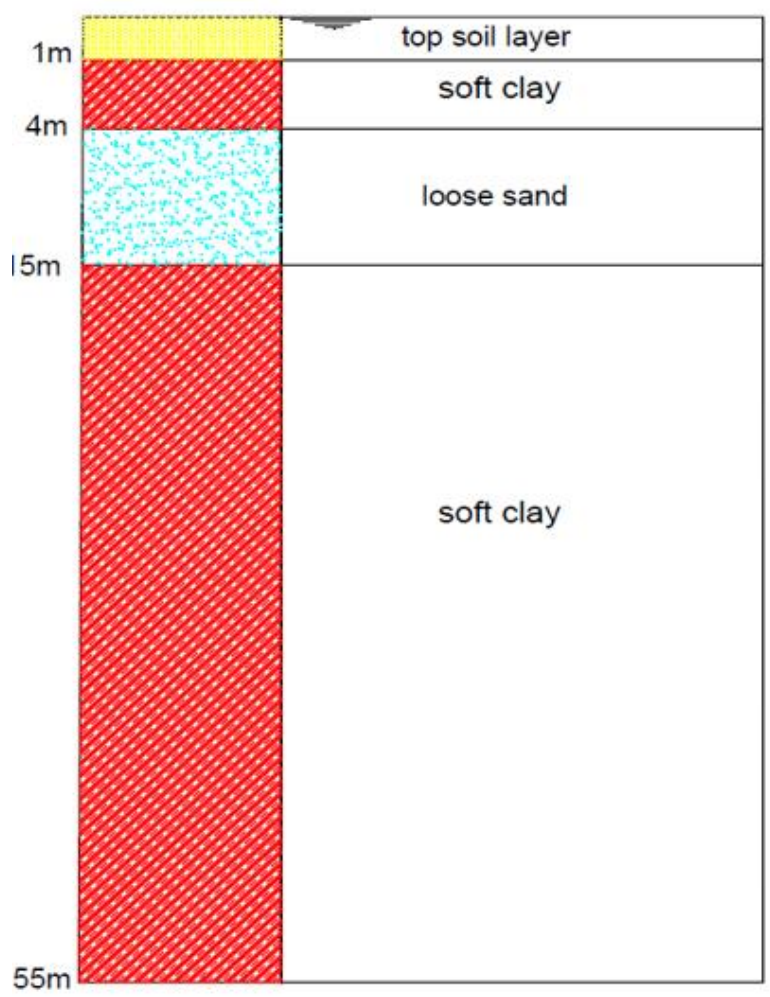

Figure (7): Special Case Soil Stratification of Port-Said Soil.

\section{4- RESULTS OF THE NUMERICAL MODEL}

In order to investigate pile behavior in the saturated loose sandy soil layer overlaying that extended compressible soils, the main factors affecting the pile capacity are exclusively studied and presented in this study. A numerical parametric study is conducted in order to explore and clarify the behavior of piles considering different practical pile configurations and soil properties. The parameters studied included the effect of 
pile length, pile diameter, embedment depth, layer depths, along with other factors.

\section{4-1- Effect of Pile Diameter}

Pile diameter is one of the most effective factors affecting the pile behavior and failure loads. Four models with different diameters $0.4,0.5,0.6$ and $0.8 \mathrm{~m}$ are studied to determine the effect of pile diameter on the pile capacity. In these models, the piles are gradually loaded up till failure. The failure of these piles is defined as the load corresponding to a settlement of 10\% of pile diameter, as per (ASTM, 2007 [7] and API RP 2, 2000 [6] , along with Terzaghi et al., 1942) [29].

For piles with length of $13 \mathrm{~m}$, the variation of pilehead settlement versus the pile failure load is studied for pile diameters of $0.4,0.5,0.6$, and $0.8 \mathrm{~m}$ respectively, as shown in Figure (8). For the four studied pile diameters it is noticed that the pile load-settlement curves have the same trend. However, a linear relationship is noticed in the load settlement curves of all the studied pile diameters, except for pile diameter of $80 \mathrm{~cm}$, indicating that the piles behave approximately elastic up till the failure load, especially for smaller pile diameters. However, near failure, the load settlement curve became relatively nonlinear for large diameter pile only, i.e., $80 \mathrm{~cm}$ diameter. This may be attributed to the larger allowable settlement at failure in this case, in which the upper sand layer affects the underlying soft clay layer. Remembering that the pile failure load is defined as the pile load corresponding to $10 \%$ of the pile diameter as mentioned before.

Pile Failure Load $(\mathrm{kN})$

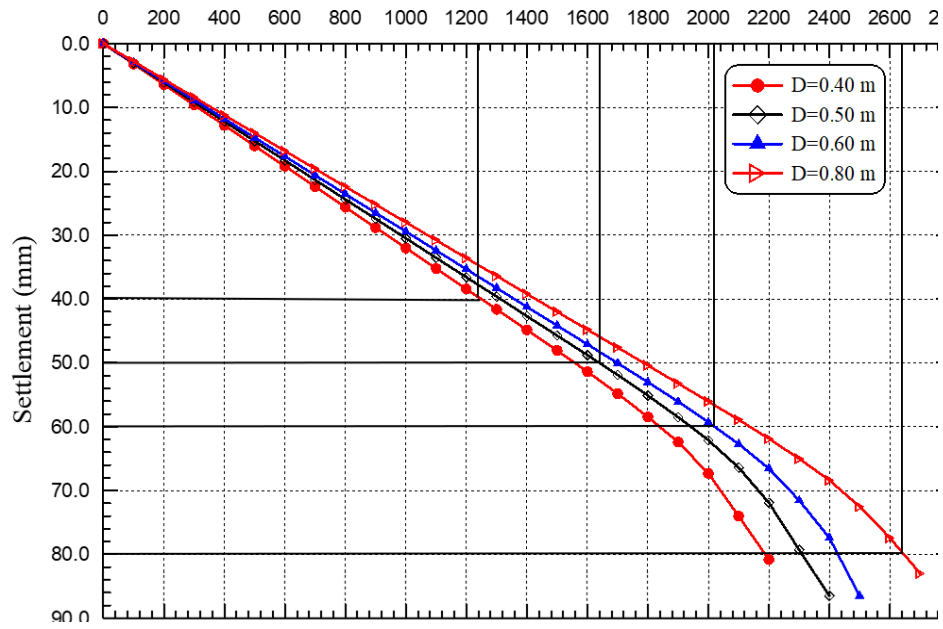

Figure (8): Load-Settlement Curves for Different Pile

Diameters.

The failure loads in this case are 1250, 1640, 2020, and $2630 \mathrm{kN}$ Respectively. In other words, pile failure loads increase about $20.7 \%, 52.6 \%$, and $93.8 \%$, for the piles with diameters $0.5,0.6$, and 0.8 compared to the failure load of the pile with diameter of $0.4 \mathrm{~m}$, which indicates a consistent and significant increase in the pile load capacity by such moderate increase in the pile diameter. Although the calculated settlements are larger for larger pile diameters but the increase in the load capacity is even higher, as presented in Figure (9) for an embedment length of $9.0 \mathrm{~m}$ within the loose sand layer.

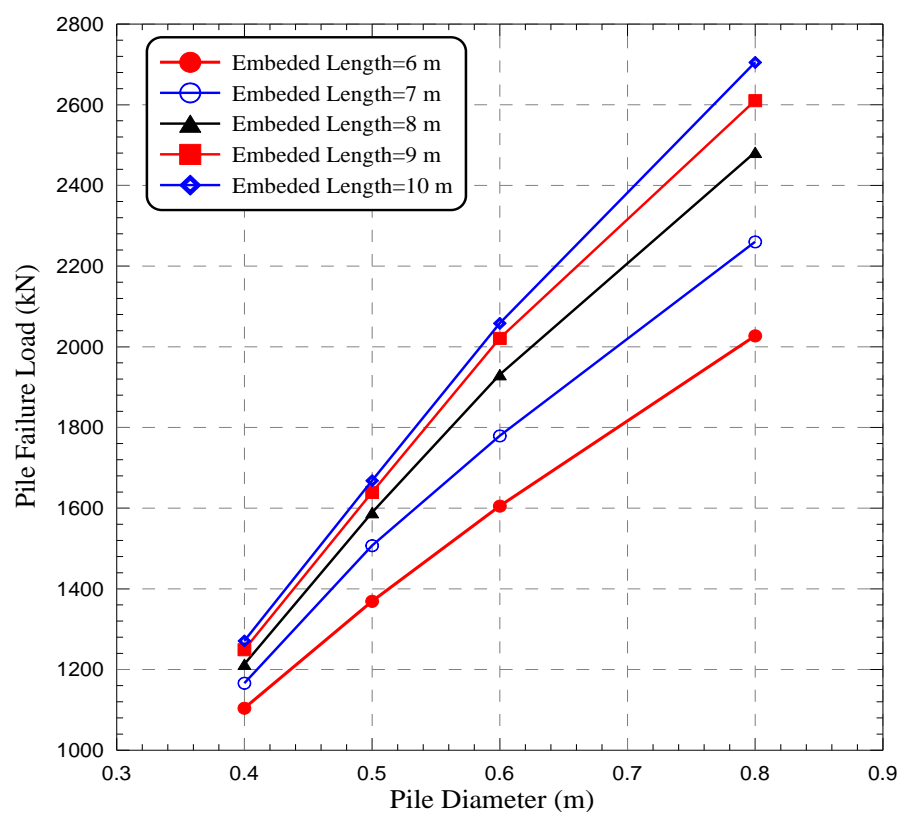

Figure (9): The Change in Pile Failure Load Versus the Change in Pile Diameter at Different Pile Lengths Embedded in Loose Sand.

Figure (10) presents color contour shading for the vertical stresses and the net displacements within the pile and soil domain for piles of $11 \mathrm{~m}$ embedment length in the loose sand layer for pile diameter of $0.80 \mathrm{~m}$. The Figure shows that a zone of about one to two the pile diameter is the most affected stress zone around the pile. At larger distances away from the pile centerline, the stresses are inversely decreasing with increasing that distance. Moreover, the stresses are concentrated along the pile circumference indicating employing all the full pile skin friction, with much less allowable end bearing values. This trend is clearly presented in Figure (16) below, in which the skin friction values are almost 3.00 times the end bearing value. In other words, the end bearing resistance is not effective in loose sand, while the skin friction is the main contributor to the pile load carrying capacity. 


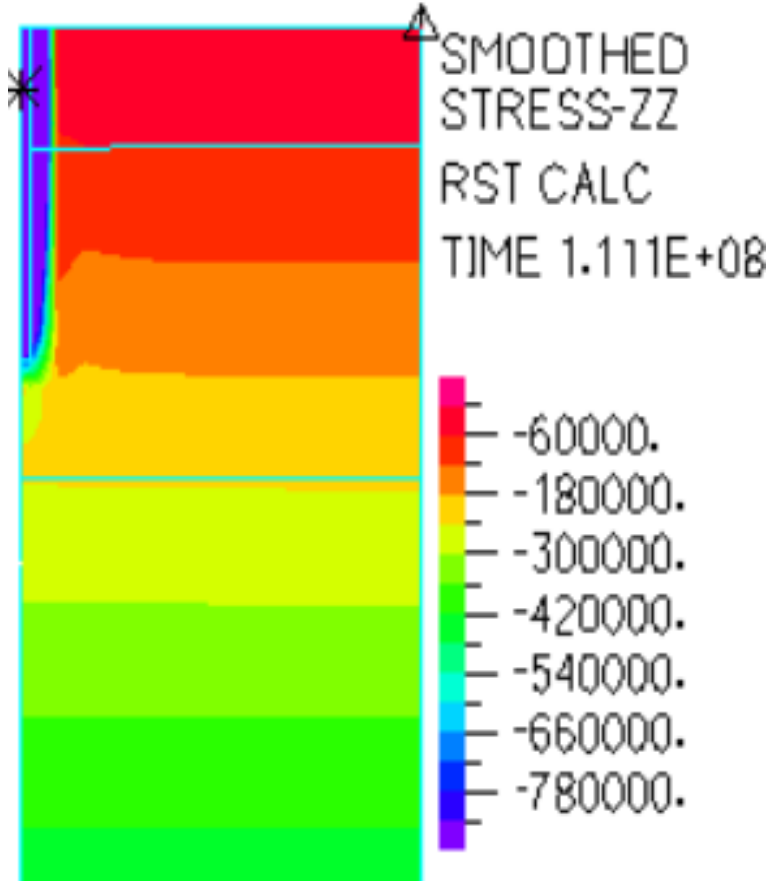

(a): Vertical Stress for Pile Diameter $0.8 \mathrm{~m}$.

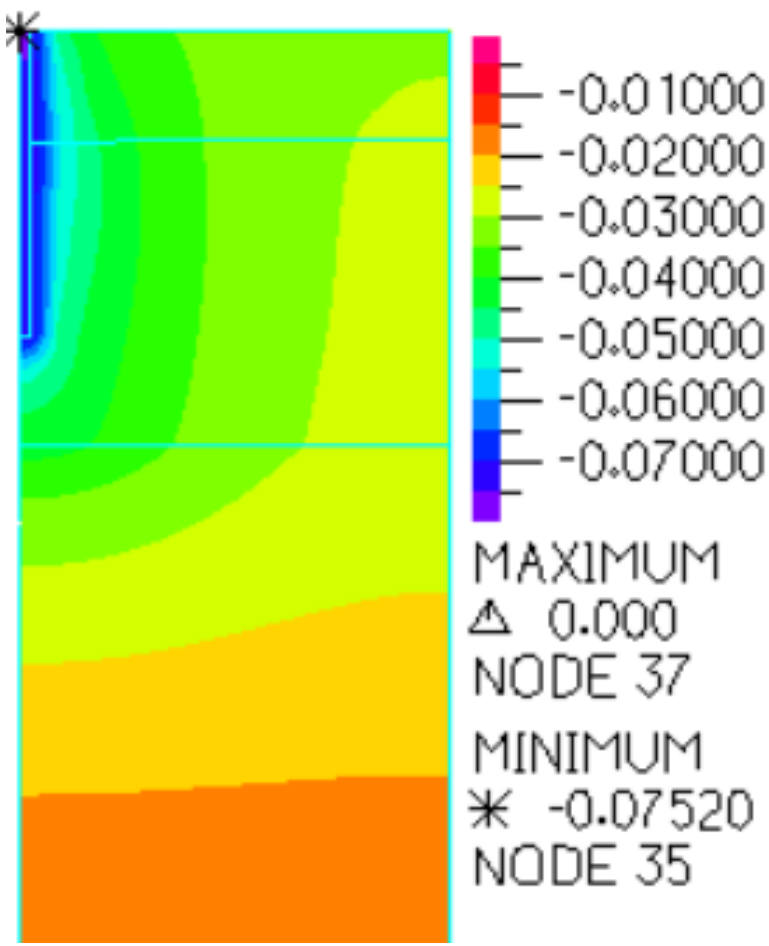

(b): Net Vertical Displacement for Pile Diameter $0.8 \mathrm{~m}$.

Figure (10): Colored Shading Contours of Vertical Stresses and Net Displacement Within the Pile and Soil Domain for Pile 11 m Length.

\section{4-2- Piles Embedment in Soft Clay Layer}

To assess the effect of pile embedment length in the soft clay, several models are created for piles with diameter ranged from 0.4 to $0.8 \mathrm{~m}$ and with lengths ranged from 16 to 18 $\mathrm{m}$. The embedment lengths inside the soft clay layer are starting from just touching the soft clay layer down to $3.00 \mathrm{~m}$. Figure (11) shows that increasing the pile embedment length within the soft clay layer has a very slight effect in increasing the pile load carrying capacity. An increase of less than $1 \%$ is noticed in such case for pile diameter of $0.40 \mathrm{~m}$ up to about $2 \%$ for pile diameter of $0.80 \mathrm{~m}$.

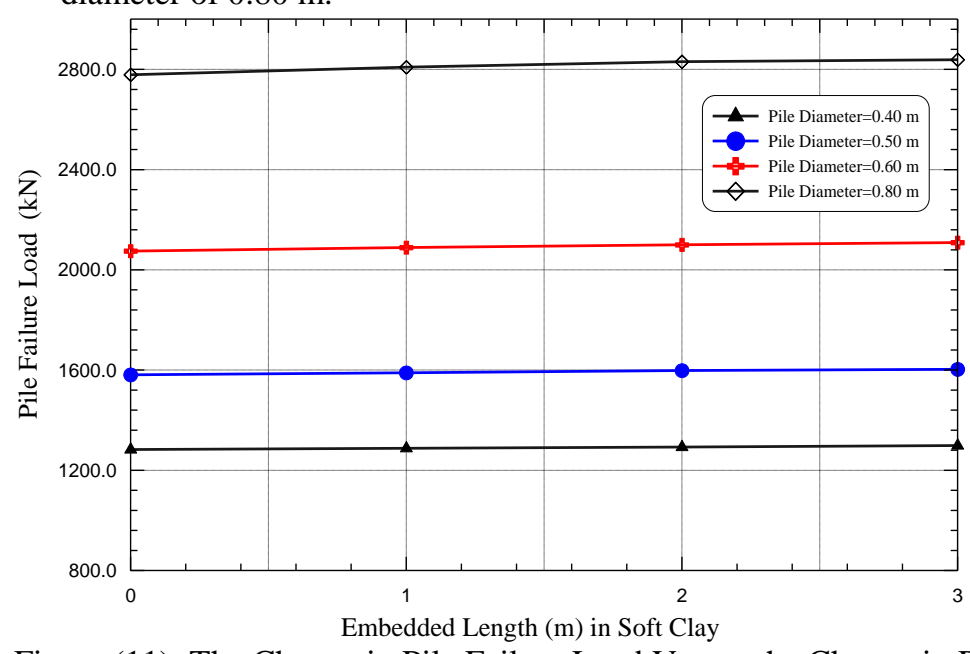

Figure (11): The Change in Pile Failure Load Versus the Change in Pile Diameter at Different Pile Lengths Embedded in Soft Clay Layer.

\section{4-3- Effect of Piles Length}

Pile lengths from 10.0 to 17.0 are studied in this case for four different pile diameters of $0.4,0.5,0.6$, and $0.8 \mathrm{~m}$, as shown in Figure (12). The loose sand layer in this case extends down to $15.0 \mathrm{~m}$, after which the extended soft clay layer is found. The Figure shows reasonable increase in the pile failure load by about $26 \%$ when increasing the pile length from 10 to $13 \mathrm{~m}$, all as long as, it lies within the sand layer. However, for pile diameters of $0.40,0.50$, and $0.80 \mathrm{~m}$ this increase is about $13 \%, 20 \%$, and $30 \%$ respectively, as shown in Figure (13). On the other hand, increasing the pile length to penetrate into the soft clay layer did not show any increase in the pile failure load, as presented by the typical load-settlement curves of lengths 15.0 up to $17.0 \mathrm{~m}$. 


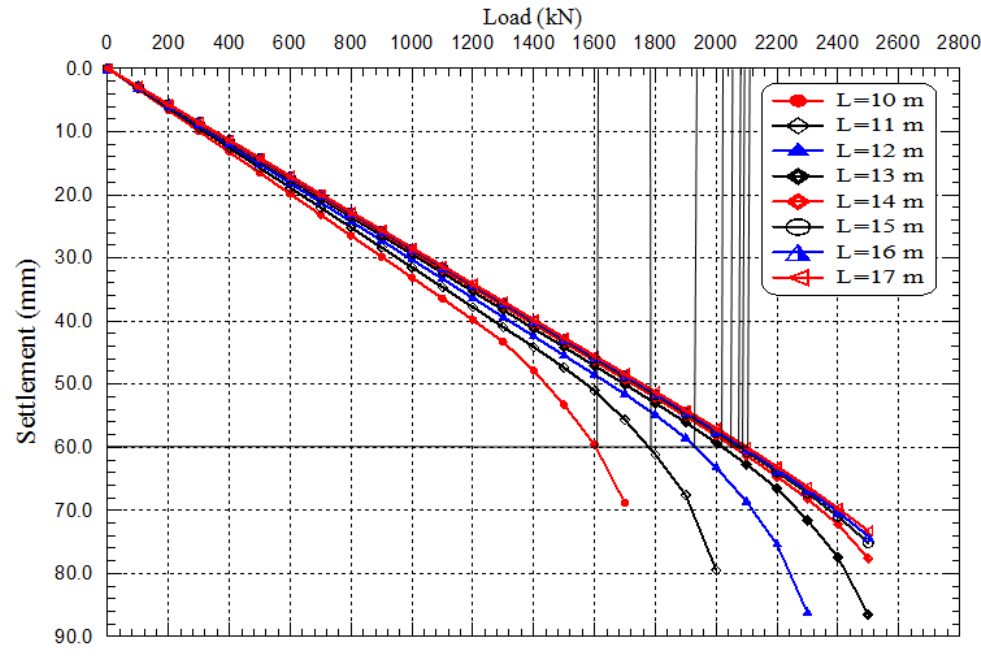

Figure (12): Load-Settlement Curves for Different Values of Pile Lengths for $0.6 \mathrm{~m}$ Pile Diameter.

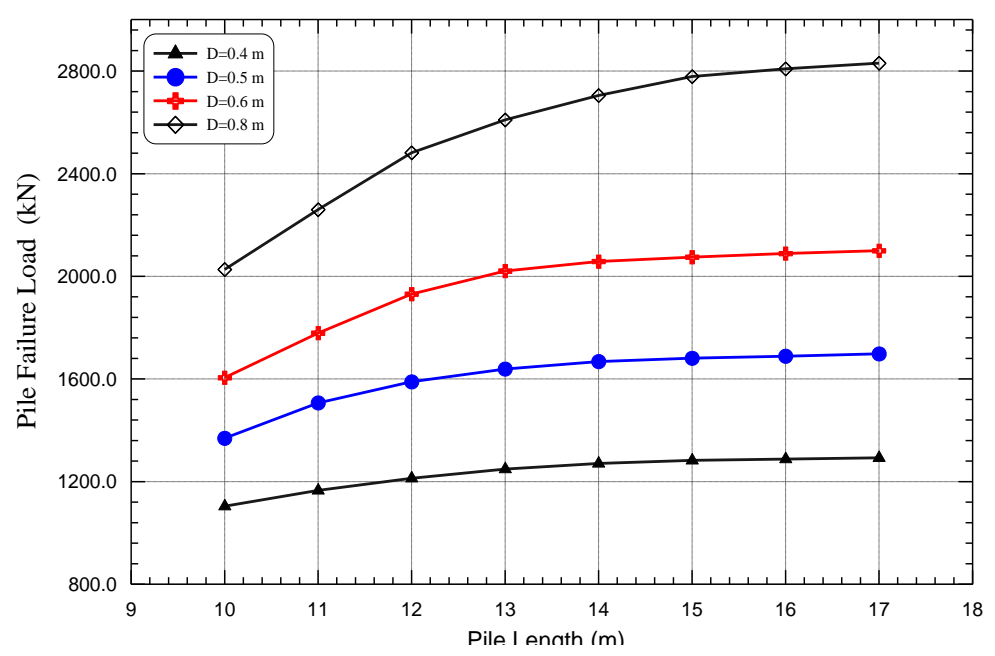

Figure (13): Relationship between Pile Failure Load and Length for Different Pile Diameters.

\section{4-4- Effect of the Thickness of Loose Sand under the Pile Tip}

In this case of the study, the thickness of the loose sand layer under the pile tip is consistently increased while keeping the pile length constant at $10.0 \mathrm{~m}$ for pile diameters of 0.40 , 0.50 , and $0.60 \mathrm{~m}$. The Figure shows that increasing the loose sand layer thickness, under the pile tip, resulted in a noticeable increase in the pile failure load up to $3.0 \mathrm{~m}$. However, increasing the thickness from $3.0 \mathrm{~m}$ to $5.0 \mathrm{~m}$ does not show the same increase. A total increase in the pile failure load ranging between 30 to $40 \%$ is noticed when increasing the thickness of the bearing layer below the pile tip from 0.0 to $5.0 \mathrm{~m}$. Once more, this behavior assures the significant effect of skin friction which controls the pile failure load, than the end bearing resistance which contributes with much less values as shown in Figure (14).

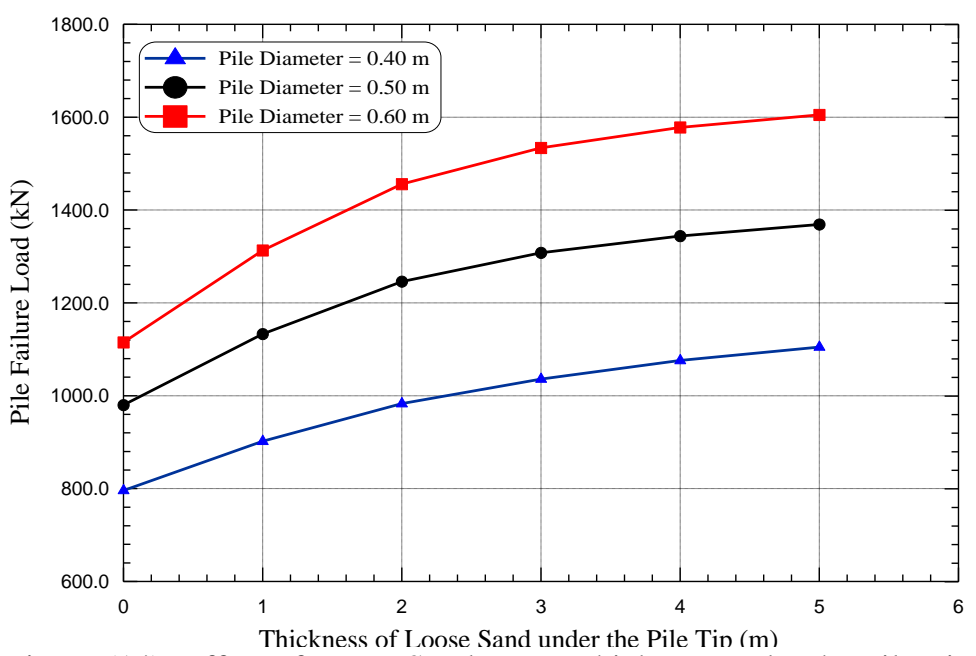

Figure (14): Effect of Loose Sand Layer Thickness under the Pile Tip on The Pile Capacity.

\section{4-5- Effect of Thickness of Upper Soft Clay Layer}

As mentioned before, the top layer in the soil formation under this study is a surface layer of soft clay with variable thickness. The reduction in thickness of the upper soft clay layer combined with increasing the loose sand layer causes an increase in the pile failure load, as a result of increasing the skin friction, due increasing the loose sand layer thickness. Figure (15) shows the effect of reducing the thickness of the upper soft clay layer on the pile failure load. Results show that reducing the thickness of the top soft clay layer from $4 \mathrm{~m}$ to 0 caused an increase in pile failure load by $11 \%$ to $17 \%$ for piles with diameter of $0.6 \mathrm{~m}$ and lengths ranging between 10 and 15 $\mathrm{m}$ respectively.4- below[3] 


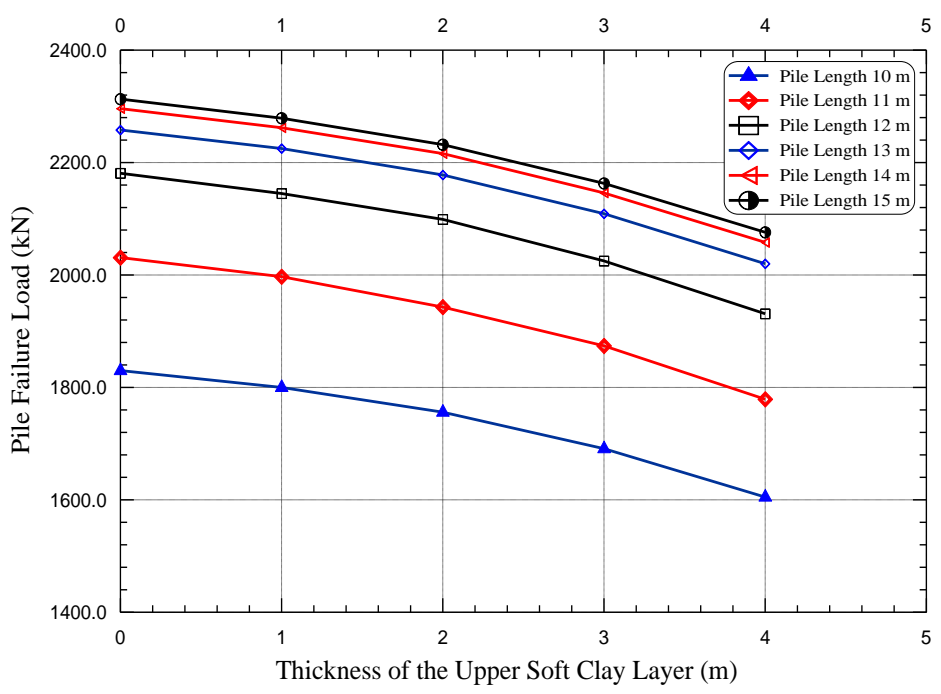

Figure (15): The Effect of Changing in Thickness of the Upper Soft Clay Layer on The Pile Failure Load.

\section{4-6-Analysis of Load Transfer Mechanism}

Due to the nature of the soil where the pile is penetrating, and due to the low value of the cohesion of soft clay combined with the friction resistance of sand layer, the pile in this study is considered a friction pile in loose sand with no significant contribution from the end bearing, as in cases of piles bearing in dense sand.

Separating the pile skin friction and end bearing resistance using results of the finite element model, it is noticed that the relationships are becoming slightly flat when the pile end bears in the soft clay layer, as shown in Figure (16). For piles with diameters 0.4 to $0.8 \mathrm{~m}$ and lengths ranged from 10 to $17 \mathrm{~m}$ the pile failure loads are calculated and both skin friction and end bearing are separated.

Increasing the pile length until the pile tip touches the soft clay layer causes the pile skin friction to increase by $53 \%$ at pile diameter equal to $0.4 \mathrm{~m}$ when increasing the pile length from 10 to $15 \mathrm{~m}$, as presented in Figure (16). However, reducing the thickness of the loose sand layer underneath the pile tip resulted in a consistent decrease in the pile end bearing resistance. Moreover, penetrating the pile tip into the soft clay layer resulted in no increase in the pile end bearing resistance. It is also found that increasing pile diameter has a significant effect on the pile skin friction resistance, and somewhat limited effect on the end bearing resistance of the piles. This behavior is ascertained by the smaller stress bulb formed under the pile tip.

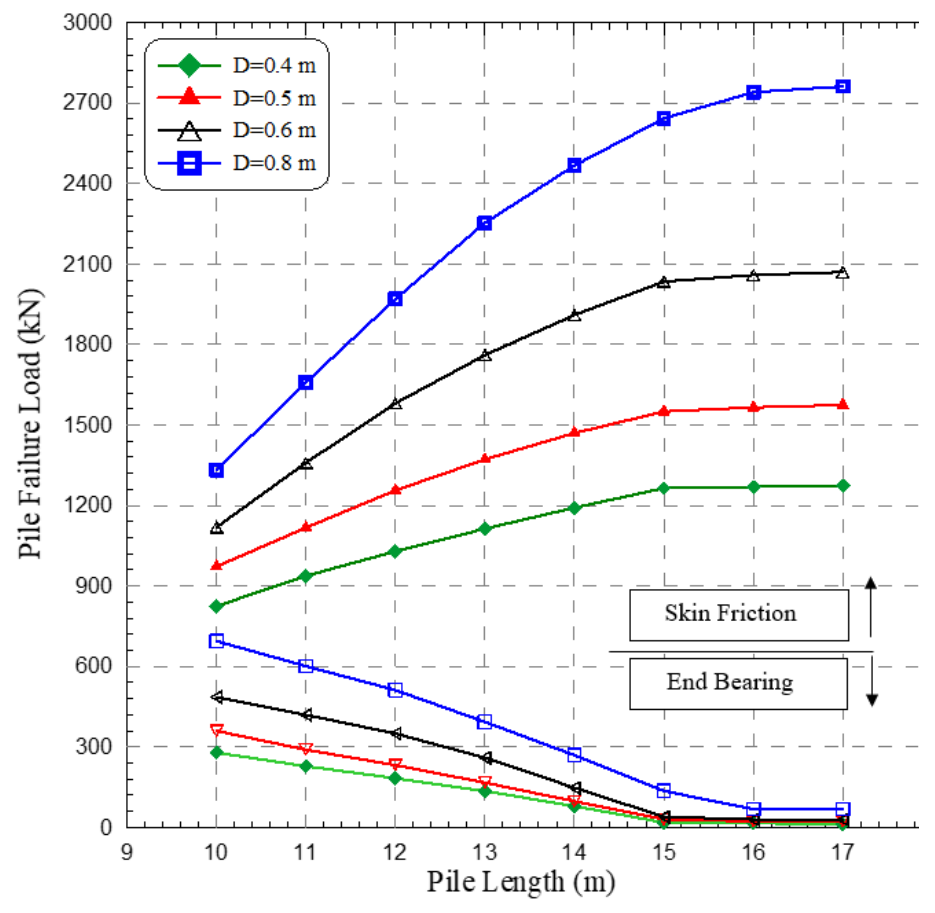

Figure (16): Separation in Pile Skin Friction and End Bearing

Resistance for Different Pile Diameters and Lengths

The percentage increase in skin friction increased with the change in pile lengths to reach $98 \%$ at pile diameter equal to 0.8 $\mathrm{m}$ with due to a change in the pile length from 10 to $15 \mathrm{~m}$, synchronized with a decrease in the end bearing resistance to be about $20 \%$ of the originally calculated end bearing value.

\section{5- CONCLUSIONS}

In the current research, results of numerical analysis of piles constructed in loose sand overlaying a deep layer of soft clay are presented. The effect of the presence of an extended soft clay layer under a single friction pile in loose to medium sand in a typical soil formation in northern zones of Egypt is studied. The typically studied case included a layer of loose sand extending down to about $15.0 \mathrm{~m}$ from the ground surface, followed by a very deep soft clay layer. The effects of pile length, pile and embedment length in sand are also considered. The main conclusions from this study are as follows:

1- Using relatively short piles constructed within the upper loose sand layer is a good economic alternative to the very deeply seated piles, or even using shallow foundations with large replacement thickness and dewatering.

2- Piles in loose sand are mainly friction piles with friction resistance of about 3.0 times the end bearing values. This behavior contradicts the cases of piles end bearing 
in dense sand, where the end bearing resistance is much higher than the skin friction values.

3- There is almost no end bearing resistance for piles end bear at the soft clay layer. Only skin friction is the key player in such case.

4- Increasing the pile diameter from 0.4 to $0.8 \mathrm{~m}$ resulted in an increase in pile failure load from $85 \%$ to $116 \%$ for piles passing through loose sand layer thickness of one and half times the pile length. On the other hand, increasing the pile embedment length in the loose sand from about $55 \%$ of the loose sand layer thickness up to its full thickness resulted in an increase in the pile failure load by $16.2 \%, 21.2 \%, 29.2$ and $37.1 \%$ for piles with diameters $0.4,0.5,0.6$ and $0.8 \mathrm{~m}$ respectively.

5- Increasing the thickness of the upper soft clay layer from 0 to about $25 \%$ of the total upper layer thickness, caused a reduction in the pile failure load by about $17 \%$ for piles with diameter of $0.6 \mathrm{~m}$ and length equal to two thirds of the upper layer thickness.

6- Reducing the failure criteria of settlement from $10 \%$ to $5 \%$ of the pile diameter, as recommended by O'Neil and Reese (1999) [27], it is noticed that the failure load is reduced by $52 \%$ for piles diameters $0.4,0.5$ and $0.6 \mathrm{~m}$ respectively

\section{6- REFERENCE}

[1] Aas, G., Lacasse, S., Lunne, T., and Hoeg, K. (1986)"Use of in situ tests for foundation design on clay." Proc., Proc. of the ASCE Conference In-situ, 130 .

[2] Abdelrahman M., Ezzeldine, O., and Salem M. 2005. "The Use of Piezocone in Characterization of Cohesive Soil West of Port Said - Egypt", Proc. of 5th Int. Geot. Eng. Conf., - Cairo University - Egypt, pp. 201-219

[3] Abdeltawab, S. and A. Hussein, 2008. Sahl Al-Tina problematic clay soils and their engineering treatment (northern Sinai Peninsula, Egypt). M.E.R.C. AinShams University, Earth Science Series, 22: 202210.

[4] ADINA Software, (2018), "Automatic Dynamic Nonlinear Analysis Software", ADINA R \& D, Inc., V.9.4.2.

[5] Ahnberg, H., Ljungkrantz, C., \& Holmqvist, L. (1995, May)," Deep stabilization of different types of soft soils". In Proceedings 11th ECSMFE, Copenhagen (Vol. 7, pp.167-172).

[6] API, R. (2000). "Recommended practice for planning, designing and constructing fixed offshore platformsworking stress design." API RP A, 2.
[7] ASTM, (2007), "Standard Test Methods for Deep Foundations under Static Axial Tensile Load", ASTM-D-3689. ASTM International, West Conshohocken, Pa.

[8] Ayman L. Fayed, Tamer M. Sorour, Hany F. Shehata: (12 July 2017), "Study of the Behavior of Floating Stone Columns in Soft Clay Formations Using Numerical Modelling".

[9] Barakat, M. K. A. (2010). "Modern geophysical techniques for constructing a 3D geological model on the Nile Delta, Egypt." Thesis dissertation. Technische Universität Berlin.

[10] Bjerrum :(1973), "Problems of soil mechanics and construction on soft clay sand structurally unstable soils". General report in Proceedings of the 8th International Conference on Soil Mechanics, Moscow, Vol. 3. pp. $111^{\wedge} 159$.

[11] El Gammal, E. (2013). "Implication of Holocene catastrophic tectonic activities on archaeological sites at Mediterranean shore North West Sinai Egypt." Aust J Basic Appl Sci, 7(9), 221-234.

[12] Eslami, A., \& Fellenius, B. H. (1997), "Pile capacity by direct CPT and CPTu methods applied to 102 case histories". Canadian Geotechnical Journal, 34(6), 886904.

[13] Hamed, O. M., Mansour, M. F., Abdel-Rahman, A. H., and El-Nahhas, F. M. (2017). "Investigating the behavior of an existing quay wall using the characteristic parameters of Port-Said Clay, Egypt." World Appl Sci J, 35(3), 483-499.

[14] Fleming, W. (1995). "The understanding of continuous flight auger piling, its monitoring and control." Proc., International Journal of Rock Mechanics and Mining Sciences and Geomechanics Abstracts, 400A.

[15] Hammam, A. H., and Salam, A. A. (2017). "Behavior of Bored Piles in Two Soil Layers, Sand Overlaying Compressible Clay (Case Study)." Proc., International Congress and Exhibition" Sustainable Civil Infrastructures: Innovative Infrastructure Geotechnology", Springer, 15-27.

[16] Hammam, A. H., and Abulied, A. F. (2017). "Settlement of Shallow Foundations on Sand Overlaying Compressible Clay, Part-I."

[17] Hamza, M., \& Shahien, M. (2013). "Compressibility parameters of cohesive soils from piezocone". In Proc. 18th Int. Conf. on Soil Mech. Geotech. Eng.

[18] HIGHT, D. (1992), "Characterization of the Bothkennar clay: implications for site investigation practice". Geotechnique, 42(2), 377-378.

[19] Ibrahim, Abdelazim Makki, Ibrahim Malik, and Omar Ataj Omar. (2012). "Assessment of load- carrying capacity of bored pile in clay soil using different methods." Vol. 2. pp.1243-1253 
[20] IBRAHEM, W. A. W. M. (2002). "Environmental geology and environmental geophysics of Northern Nile Delta in terms of neotectonics and physical processes". (Doctoral dissertation, A thesis submitted in partial fulfillment for the degree of Master of Science in geology, Damietta Faculty of Science).

[21] Ismail, A., and Ryden, N. (2012). "Engineering geological characteristics of soil materials, East Nile Delta, Egypt." Sea, 31, 30.

[22] Ismail, A. I. M., \& Ryden, N. (2014), "The quality control of engineering properties for stabilizing silty Nile Delta clay soil, Egypt". Geotechnical and Geological Engineering, 32(4), 773-781.

[23] Jamiolkowski, M., Ladd, C. C., Germaine, J. T., \& Lancellotta, R. (1985). "New Developments in Field and Laboratory Testing of Soils. Proceedings of The Eleventh International Conference on Soil Mechanics and Foundation Engineering”. SAN FRANCISCO, 12-16 AUGUST 1985. Publication of: Balkema (AA).

[24] King, G. J. W., Dickin, E. A., Lyndon, A., \& Wei, M. J. (2000), "The influence of rate of loading on the behavior of continuous-flight-auger bored piles in soft clay”. Geotechnical \& Geological Engineering, 18(2), 139-153.

[25] Randolph, M. F., and Wroth, C. P. (1978). "Analysis of deformation of vertically loaded piles." Journal of Geotechnical and Geoenvironmental Engineering, 104(ASCE 14262).

[26] Shi, B., \& Kong, X. (2017, July), "Study on Methods for Predicting the Settlements of Soft Clay Roadbed. In International Congress and Exhibition" Sustainable Civil Infra-structures: Innovative Infrastructure Geotechnology" (pp. 370-377).

[27] O'Neil, M. W., \& Reese, L. C. (1999). Drilled shafts: Construction procedures and design methods (No. FHWA-IF-99-025,).

[28] Stanley, D. J. (2004). "Nile delta margin: failed and fluidized deposits concentrated along distributary channels." Geomorphologic.

[29] Terzaghi, K. (1942). "Discussion of the progress report of the committee on the bearing value of pile foundations." Proc., Proceedings, ASCE, 311-323.a 